DOI 10.37882/2223-2966.2020.10.01

\title{
ИССЛЕДОВАНИЕ АЭРОТЕХНОГЕННОГО ЗАГРЯЗНЕНИЯ НА ТЕРРИТОРИИ МУРМАНСКОЙ ОБЛАСТИ С ИСПОЛЬЗОВАНИЕМ СОСНЫ ОБЫКНОВЕННОЙ
}

\section{STUDY OF AEROTECHNOGENIC POLLUTION IN THE TERRITORY OF THE MURMANSK REGION USING THE SAMPLES OF COMMON PINE}

E. Alexandrova

A. Trotcenko

Summary: The article presents the results of a bio-indicative assessment of the state of the environment in the impact zone of the Severonikel integrated industrial complex. It assesses the general state of conifers, determines their stability class, studies the morphometric characteristics of common pine needles, and environmental classes of the target area. Within the framework of the study, we noted a decrease in the linear parameters of the needles, a deterioration in the vital state of the trees when approaching the area of technogenic impact of the Severonikel plant. The state of the environment in Monchegorsk district of the Murmansk region was also determined: up to $20 \mathrm{~km}$ from the source of exposure - a zone of increased environmental hazard, 20-30 km - a zone of relative ecological well-being, over $70 \mathrm{~km}$ - an environmentally safe zone.

Keywords: aerotechnogenic pollution, bioindication, common pine, morphometric characteristics of needles, state of the environment.
Александрова Евгения Юрьевна

К.п.н., доцент, ФГБОУ ВО «Мурманский арктический государственный университет» (2. Мурманск)

dzhessika_www@mail.ru

троченко Алла Анатольевна

К.б.н., дочент, ФГБОУ ВО «Мурманский арктический государственный университет» (2. Мурманск)

Аннотация: В статье представлены результаты фитоиндикационной оценки состояния природной среды В районе воздействия промышленного комбината «Североникель». Проведена оценка общего состояния хвойных растений, определен класс их устойчивости, изучены морфометрические характеристики хвои сосны обыкновенной, определены классы состояния окружающей среды в исследуемом районе. В рамках исследования отмечено уменьшение линейных параметров хвои, ухудшение жизненного состояния деревьев при приближении к зоне техногенного воздействия со стороны комбината «Североникель». Определено состояние окружающей среды в Мончегорском районе Мурманской области: до 20 км от источника воздействия - зона повышенного экологического риска, 20-30 км - зона относительного экологического благополучия, более 70 км - экологически безопасная зона.

Ключевые слова: аэротехногенное загрязнение, биоиндикация, сосна обыкновенная, морфометрические характеристики хвои, состояние окружающей среды.

мечает Е.Г. Мозолевская, среди характерных признаков ухудшения качества среды можно отметить появление на ассимиляционных органах хлорозов и некрозов, снижение морфометрических характеристик (толщины и длины побега, длины хвои, размера шишек, уменьшение количества почек и ветвления) [5].

Определению состояния природной среды по отклонению морфометрических характеристик растений посвящены многочисленные исследования. Как показал ранее проведенный нами анализ теоретико-методологических работ с использованием хвойных растений, особую популярность среди биоиндикаторов приобрела сосна обыкновенная (Pinus sylvestris L.).

Потенциал хвойных растений как биоиндикаторов привлекает внимание ученых и Кольского Севера, где обнаруживается повышенное техногенное давление на окружающую среду. В то же время, данные исследования актуальны и требуют своего продолжения. 
Цель исследования: изучение отклонений в морфометрических характеристиках хвои сосны обыкновенной (Pinus sylvestris L.) в районе воздействия комбината «Североникель».

Задачи исследования: определение степени повреждения хвои сосны обыкновенной в ходе дигрессионной сукцессии; анализ морфометрических характеристик хвои как параметров ростовых процессов; выявление зон экологического благополучия и риска в исследуемом районе.

В соответствии с методикой 3.П. Оказовой и др. [6] впервые выделены зоны экологического благополучия в Мончегорском районе, а также определены стадии антропогенной дигрессии сосновых лесов Мурманской области на удалении от источника воздействия. В более ранних наших исследованиях проводился сравнительный морфометрический анализ различных хвойных растений, но зоны экологического благополучия и стадии антропогенной дигрессии по сосне обыкновенной в исследуемом районе не определялись.

\section{Характеристика района исследования}

Мурманская область расположена на Кольском полуострове, который занимает по площади 89 тыс. км² и практически полностью находится за Полярным кругом. Здесь распространены кустарничково-лишайниковые сосняки, кустарничковые и зеленомошно-кустарничковые ельники с березой.

Важным промышленным горно-добывающим и перерабатывающим центром в Мурманской области является Мончегорский район, где основное загрязнение обусловлено поступлением тяжелых металлов, углеводородов, соединений углерода и азота со стороны комбината «Североникель». Исследования, проводимые ранее в данном районе (Т.В. Арсеньева, Е.С. Чавчавадзе [2], Г.Н. Копцик [3], М.Г. Опекунова [7], Н.В. Салтан [8], В.Т. Ярмишко [10] и др.), свидетельствуют об интенсивном образовании кислотных осадков, деградации почвенного покрова, снижении биоразнообразия и значительном угнетении лесной растительности.

Необходимо отметить, что модернизация материально-технологической базы крупных промышленных объектов Мончегорского района несколько снизила загрязнение, но до сих пор отмечается высокая концентрация тяжелых металлов в хвойных растениях, кустарниках и грибах [7, с. 75]. Максимальные концентрации загрязняющих веществ зафиксированы на удалении около 8 км от источника воздействия (стадия техногенного редколесья).

Популяция хвойных растений на Кольском Севере представляет северный предел своего ареала. При этом деревья, произрастающие в зоне воздействия комбината «Североникель», десятилетиями испытывают высокую техногенную нагрузку (выбросы сернистого ангидрида, тяжелых металлов) [3, с. 145; 7, с. 71; 8, с. 801]. При приближении к источнику воздействия в структуре сообществ отмечается выпадение лишайников и мхов, снижение количества кустарничковой растительности при доминировании злаковых, отмирание подроста и низкорослость древостоя. На стадии техногенной пустоши (до 7 км) хвойные растения отсутствуют, формируется березовое редколесье. Встречается береза субарктическая (Betula subarctica O.) и ива козья (Salix caprea L.), большинство из которых сильно ослаблены.

Исследования, проводимые в данном районе в 19812008 гг., показали, что в буферной зоне наблюдалось значительное снижение степени дефолиации (на 20\%), увеличение видового многообразия (на 34\%). Подобные тенденции были отмечены исследователями и для импактной зоны (5-7 км), где зафиксировано увеличение количества видов растений примерно в 2 раза [9, с. 56]. У хвойных растений обнаруживается усиление роста верхушечных побегов и радиального прироста, что свидетельствует о начале восстановительной сукцессии.

Как отмечает И.В. Лянгузова, при сохраняющемся техногенном давлении со стороны комбината «Североникель» усиливается деградация почвенного покрова, а улучшения наблюдаются только лишь у древесной растительности. В то же время положительная реакция на уменьшение выбросов в атмосферу со стороны отдельных компонентов биогеоценозов неоднозначна: наблюдается запаздывание и даже отсутствие положительной динамики, например, у Vaccinium myrtillus L., остается неясной реакция хвойных растений $[4$, c. 5].

\section{Характеристика объекта исследования}

Объектом исследования являлась сосна обыкновенная (Pinus sylvestris L.), произрастающая в кустарничковолишайниковых сосняках северной подзоны восточноевропейской тайги.

Сосна обыкновенная характеризуется обширным ареалом обитания на территории нашей страны. Это довольно высокие быстрорастущие деревья - от 20 до 40 метров в высоту, по обхвату ствола могут достигать до 1 метра. Активный рост обусловлен благоприятными температурами воздуха и значительным количеством осадков в вегетационный период. Молодые формы имеют ширококоническую крону, которая с возрастом постепенно превращается в яйцевиднораскидистую [2, с. 32]. В поперечном сечении хвоя сосны обыкновенной имеет плосковыпуклую форму, довольно жесткая, достигает длины 4-7 см. 
Отличительной особенностью сосны обыкновенной является тот факт, что она не требовательна к почвенным условиям, способна произрастать на малогумусовых и даже заболоченных почвах. Лучший рост деревьев обеспечивается на песчаных и супесчаных почвах.

Удобство хвойных пород определяется также тем, что они имеют многолетнюю хвою. В природных экосистемах возраст хвои зависит от породы. Так, хвоя сосны варьирует от 3-4 лет (у южных форм) до 8-9 лет (у северных форм). При этом многочисленными исследованиями подтверждено, что атмосферное загрязнение значительно сокращает продолжительность жизни хвои. На некоторых объектах обнаруживается древостой исключительно с однолетней хвоей.

Как отмечает М.Г. Опекунова, в районе воздействия комбината «Североникель» зафиксировано хроническое загрязнение атмосферы диоксидом серы, примесями тяжелых металлов (никеля, меди, кобальта и др.), в связи с чем возраст хвои сосны обыкновенной уменьшается до 2-4 лет, тогда как в естественных условиях возраст увеличивается до 6-7 лет) [7, с. 77]. Исследования, проведенные в Мурманской области В.Т. Ярмишко, также подтверждают достоверную корреляционную связь уменьшения радиального прироста сосны обыкновенной, уменьшения размеров хвои, сокращения продолжительности жизни хвои с увеличением выбросов со стороны комбината «Североникель» [10].

В условиях загрязнения окружающей среды уменьшается масса, длина хвои, снижается содержание всех пигментов, что приводит к осветлению хвои и переходу от темно-зеленого к светло-зеленому оттенку. Наряду с этим уменьшается влажность хвои сосны обыкновенной при ухудшении экологической обстановки, что связано со снижением активности метаболизма. Все эти индикаторные признаки позволяют использовать данный объект при проведении оценки состояния окружающей среды.

\section{Материалы и методы}

Исследование проводилось в июне 2020 г. Для организации процедуры исследования были заложены 5

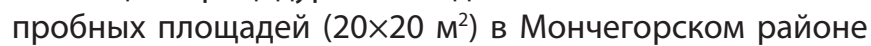
(северо-восточное направление) на различном удалении от источника воздействия (комбинат «Североникель»), а также 2 условно фоновые площади (на значительном удалении от источника загрязнения, 70 и 90 км).

Закладка пробных площадей осуществлялась, исходя из стадий техногенной сукцессии (класса лесных экосистем) [6]: до 5 км - стадия техногенной пустоши (импактная зона, полностью разрушенные экосистемы, хвойные растения отсутствуют, пробная площадь не за- кладывалась); 10 и 15 км - стадия техногенного редколесья (отмирающий древостой, ПП-1 и ПП-2); 20 км - стадия интенсивной дефолиации (сильно поврежденный древостой, ПП-3); 25 км - стадия дефолиации (поврежденный древостой, ПП-4); 30 км - стадия начальной дефолиации (древостой начального повреждения, ПП-5); 70 и 90 км - условно фоновый тип состояния (ненарушенный древостой, древостой начального повреждения, ПП-6 и ПП-7).

Оценка общего состояния хвойных растений в исследуемом районе проводилась по Е.Г. Мозолевской, определялся класс устойчивости (1-3) исследуемых деревьев: биологически устойчивые, нарушенная устойчивость, утратившие устойчивость [5, с. 53].

Исходя из того, что хвойные растения в импактной зоне немногочисленны (обнаруживается от 1-2 до 5-7 экземпляров), на каждой пробной площади отбиралась хвоя 5-ти исследуемых деревьев, далее она группировалась по возрастным группам.

Для исследований наибольший интерес представляет молодая хвоя. Это обусловлено тем, что старовозрастной хвое характерна выработка адаптационных механизмов биосинтеза к негативным условиям среды. В связи с этим, нами для анализа отбиралась хвоя 1-2 года жизни.

В соответствии с методикой 3.П. Оказовой и др. [6], хвоя отбиралась на высоте около 1,5 м с части кроны, обращенной к источнику загрязнения. Затем осуществлялось определение состояния природной среды на основании соответствия хвои биологическим особенностям вида, проводились замеры и расчеты морфометрических характеристик хвои, анализировались хлорозы и некрозы.

Для оценки состояния окружающей среды в исследуемом районе изучался класс усыхания и класс повреждения хвои: 1 класс состояния (экологически безопасная зона) - 95-100\% соответствует биологическим особенностям сорта хвойного дерева (хвоя без пятен, усыхание отсутствует); 2 класс (зона относительного экологического благополучия) - 80-94\% (хвоя с небольшим количеством пятен, усыхание не более 1/3 длины хвои); 3 класс (зона повышенного экологического риска) $<80 \%$ (хвоя с большим количеством пятен, усыхание более 1/2 длины хвои). Повреждения тканей определялись визуально по изменению цвета хвои - дехромации (анализировалась площадь хлорозов и некрозов хвои).

Дополнительными интегрирующими показателями, усредняющими морфометрическую структуру хвои, являются полусферическая и общая поверхность хвои на разных участках. При значительном различии в раз- 
мерах хвои (17-20\%), их общая и полусферическая поверхности могут быть практически одинаковыми (2-4\%) у разных образцов. Это подтверждается нашими более ранними морфометрическими исследованиями. В связи с этим нами был проведен расчет общей поверхности хвои.

Достоверность полученных результатов оценивали с помощью статистического критерия Фишера (F-критерий, $\varphi^{*}$-критерий) для независимых выборок, сравниваемых попарно, со статистической значимостью $\mathrm{p} \leq 0,01$ с учетом коэффициента дисперсии. Вероятность групповой ошибки контролировалась с помощью коррекции Бонферрони, а критический уровень значимости составлял 0,011.

\section{Результаты и обсужление}

Проведенное исследование позволило выделить основные классы устойчивости древостоя в исследуемом районе (рис. 1). Свою биологическую устойчивость хвойные растения начинают восстанавливать на расстоянии 30 км и более от комбината «Североникель».

Сильное атмосферное загрязнение усиливает дехромацию и дефолиацию кроны деревьев, у подроста они выражены слабее. Хлорозы приурочены, в основном, к верхушечной части хвоинок, также обнаруживаются микроскопические пятна некрозов из-за проникновения загрязняющих веществ через устьица и разрушенную кутикулу. Хлорозы зачастую отсутствуют у однолетних побегов.

На пробных площадях №1-2 (10-15 км) класс повреждения хвои сосны обыкновенной составляет 3 балла, обнаруживаются многочисленные точечные повреждения хвои, наблюдается усыхание кончиков. При этом умень- шается и возраст хвои (2-4 года), тогда как в естественных условиях он составляет 6-7 лет. На пробных площадях №6-7 (фоновая зона) возраст хвои составил 4-5 лет.

Накопление загрязняющих веществ приводит к отклонению в морфометрических характеристиках хвои. Средняя длина старовозрастной хвои в исследуемом районе изменяется от 31,25-33,5 мм в импактной зоне до 36,5-41,0 мм в фоновой зоне. Процент повреждения хвои снижается с увеличением расстояния от комбината «Североникель» (от 60\% вблизи источника загрязнения до 4,3\% - на удалении в 30 км). Для молодой хвои 1-2 года жизни результаты представлены в таблице 1.

Отмечено снижение длины хвои 1-2 года по сравнению с контрольными образцами ( $\left.\varphi^{*}>\varphi_{\text {кр }} ; \mathrm{p} \leq 0,01\right)$. При анализе ширины хвои подобная зависимость наблюдается не всегда: иногда встречается одинаковая ширина хвои как у фоновых образцов, так и у образцов в импактной зоне. Такие вариации ширины хвои обнаруживались нами и ранее, в исследованиях ели сибирской [1, с. 10].

В рамках исследования отмечено уменьшение линейных параметров хвои, ухудшение жизненного состояния деревьев при приближении к зоне техногенного воздействия со стороны комбината «Североникель». В зоне техногенного редколесья возрастает количество деревьев с искривлением стволов и побегов, суховершинностью, несимметричностью кроны, неравномерной охвоенностью побегов.

По результатам исследования определено состояние окружающей среды в Мончегорском районе Мурманской области: до 20 км от источника воздействия - зона повышенного экологического риска, 20-30 км - зона относительного экологического благополучия, более 70 км - экологически безопасная зона.

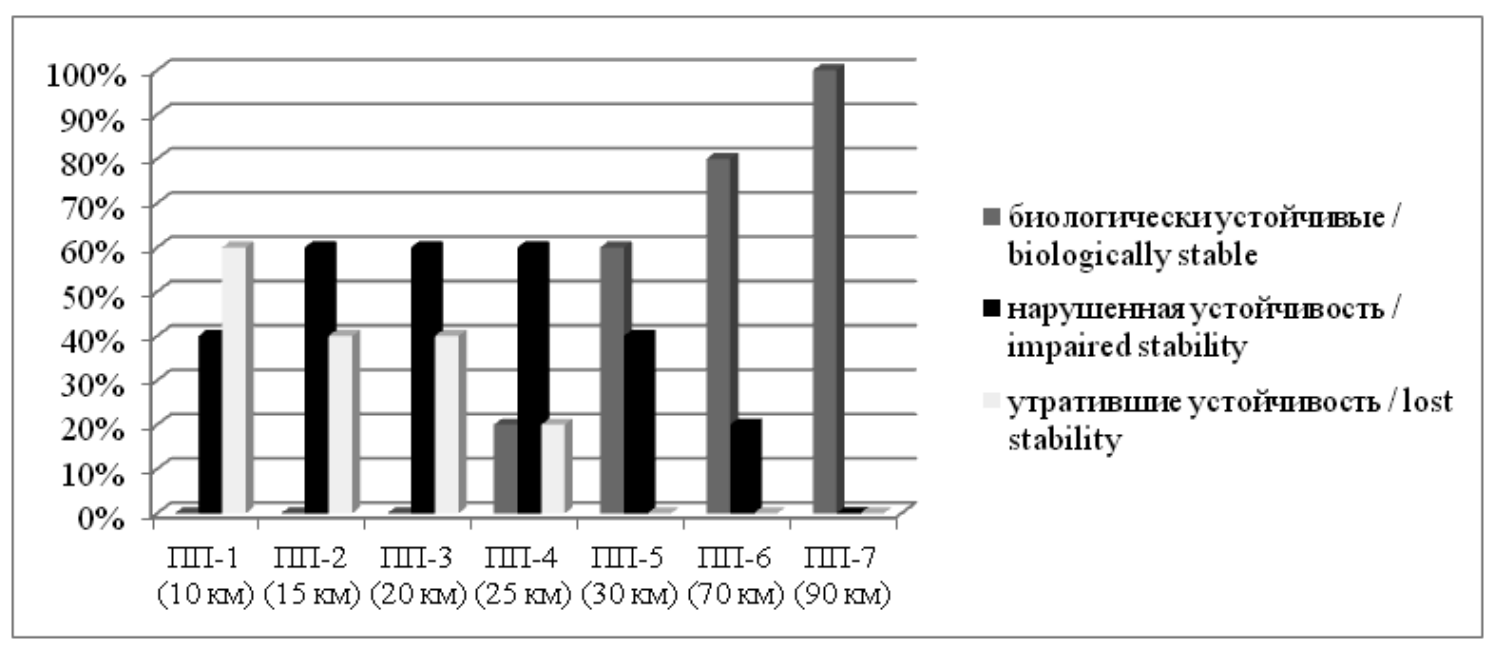

Рис. 1. Распределение хвойных по классам устойчивости (в \%) в зависимости от удаления от источника воздействия 
Таблица 1.

Морфометрические характеристики хвои 1-2 года жизни в исследуемом районе

\begin{tabular}{|c|c|c|c|c|l|}
\hline Пробная площадь & $\begin{array}{c}\text { Средняя длина } \\
\text { молодой хвои (мм) }\end{array}$ & $\begin{array}{c}\text { Средний } \\
\text { \% повреждений }\end{array}$ & $\begin{array}{c}\text { 0бщая поверхность } \\
\text { хвои (мм²) }\end{array}$ & $\begin{array}{c}\text { Класс повреждения } \\
\text { хвои }\end{array}$ & $\begin{array}{c}\text { Состояние } \\
\text { окружающей среды }\end{array}$ \\
\hline ПП-1 (10 км) & 20,25 & 31,25 & 54,87 & 3 & 30на повышенного экологического риска \\
\hline ПП-2 (15 км) & 23,00 & 31,25 & 65,02 & 3 & 30на повышенного экологического риска \\
\hline ПП-3 (20 км) & 24,50 & 30,00 & 69,26 & 3 & зона повышенного экологического риска \\
\hline ПП-4 (25 км) & 23,70 & 10,00 & 66,91 & 2 & $\begin{array}{l}\text { 30на относительного экологического } \\
\text { благополучия }\end{array}$ \\
\hline ПП-5 (30 км) & 26,50 & 12,50 & 74,92 & 2 & $\begin{array}{l}\text { зона относительного экологического } \\
\text { благополучия }\end{array}$ \\
\hline ПП-6 (фон) & 28,65 & 3,25 & 80,99 & 1 & экологически безопасная зона \\
\hline ПП-7 (фон) & 28,15 & 2,00 & 79,58 & 1 & экологически безопасная зона \\
\hline
\end{tabular}

\section{Зак^ючение}

Как показало проведенное исследование, аэротехногенное загрязнение воздействует на все компоненты лесной растительности. Происходит отмирание древостоя, разрушение нижних ярусов и внеярусной растительности, необратимые изменения и последующая эрозия почв. Наиболее чувствительны зеленые мхи, кустарничковый ярус довольно устойчив, хотя его проективное покрытие вблизи зоны высокой антропогенной нагрузки значительно снижается.

На удалении 0-5 км от комбината почва сохраняется исключительно под отдельными куртинами сильно поврежденных лиственных пород деревьев (береза, ива), хвойные в этой зоне отсутствуют.

После поступления токсикантов в органы хвойных растений начинается их включение в клеточные процессы. При этом основные видимые морфологические проявления со стороны хвойных растений (гибель, снижение биомассы растений, хлорозы, некрозы) наступают, когда превышена граница адаптационной способности и системы поддержания жизнедеятельности растения становятся нестабильными.

Высокое техногенное загрязнение обуславливает по- вышенную степень дехромации и дефолиации кроны сосны, у подроста это выражено слабее.

Наблюдаются значительные отклонения естественных значений морфометрических характеристик для хвои Pinus sylvestris L. в зоне воздействия комбината «Cевероникель»: уменьшение длины и общей поверхности хвои, сокращение продолжительности жизни хвои, увеличение повреждений хвои.

В ходе дигрессионной сукцессии наблюдается нелинейная изменчивость морфометрических характеристик для хвои Pinus sylvestris $L$. Данная зависимость в исследуемом районе отмечалась нами и ранее при анализе других хвойных пород [1].

Наименьшая общая поверхность свойственна однолетней хвое на стадии техногенного редколесья. На стадии интенсивной дефолиации длина и общая поверхность хвои увеличиваются, в то время как на последующих стадиях наблюдается уменьшение морфометрических характеристик. Это можно объяснить тем, что при уменьшении (до уровня дефицита) концентрации кальция и магния наблюдается обратная тенденция, когда на стадии техногенного редколесья и стадии затухающей дефолиации усиливается синтез вторичных метаболитов, а размеры хвои уменьшаются.

\section{ЛИТЕРАТУРА}

1. Александрова Е.Ю., Воронов А.А. Морфометрические характеристики хвои ели сибирской в зоне воздействия комбината «Североникель» // Современная наука: актуальные проблемы теории и практики. Серия: Естественные и технические науки, 2020, № 05, с. 7-12.

DOI: $10.37882 / 2223-2966.2020 .05 .01$.

2. Арсеньева Т.В., Чавчавадзе Е.С. Эколого-анатомические аспекты изменчивости древесины сосновых из промышленных районов Европейского Севера. СПб: Наука, 2001, 109 c.

3. Копцик Г.Н., Копцик С.В., Смирнова И.Е., Кудрявцева А.Д., Турбабина К.А. Реакция лесных экосистем на сокращение атмосферных промышленных выбросов в Кольской субарктике // Журнал общей биологии, 2016, т. 77, № 2, с. 145-163. 
4. Лянгузова И.В. Толерантность компонентов лесных экосистем Севера России к аэротехногенному загрязнению. Автореф. дис. д-ра биол. наук. СПб: Ботан. ин-т им. В.Л. Комарова, 2010, 39 с.

5. Мозолевская Е.Г., Голубев А.В., Шарапа Т.В. Методы оценки состояния насаждений и негативной роли вредителей и болезней // Лесной вестник, 2013, № 3, c. 52-57.

6. Оказова 3.П., Кусова Н.Х., Басиев В.А., Ефанов М.В., Кадзаева 0.Э. Способ оценки состояния окружающей среды // Патент RU 2564916 C2. Заявка: 2013141861/15, 12.09.2013. Дата публикации: 10.10.2015. Бюлл. 28.

7. Опекунова М.Г., Елсукова Е.Ю., Чекушин В.А. Мониторинг изменения состояния окружающей среды в зоне воздействия комбината «Североникель» с помощью методов биоиндикации // Вестник СПбГУ, сер. 7, 2007, вып. 1, с. 71-79.

8. Салтан Н.В. Динамика содержания тяжелых металлов в ассимилирующих органах растений локальной зоны воздействия комбината «Североникель» // Вестник МГТУ, 2013, т. 16, № 4, с. 793-802.

9. Черненькова Т.В., Кабиров Р.Р., Басова Е.В. Восстановительные сукцессии северотаежных ельников при снижении аэротехногенной нагрузки // Лесоведение, 2011, № 6, с. 49-66.

10. Ярмишко В.Т. Сосна обыкновенная и атмосферное загрязнение на Европейском Севера. СПб: НиИ химии СПбГу, 1997, 210 с.

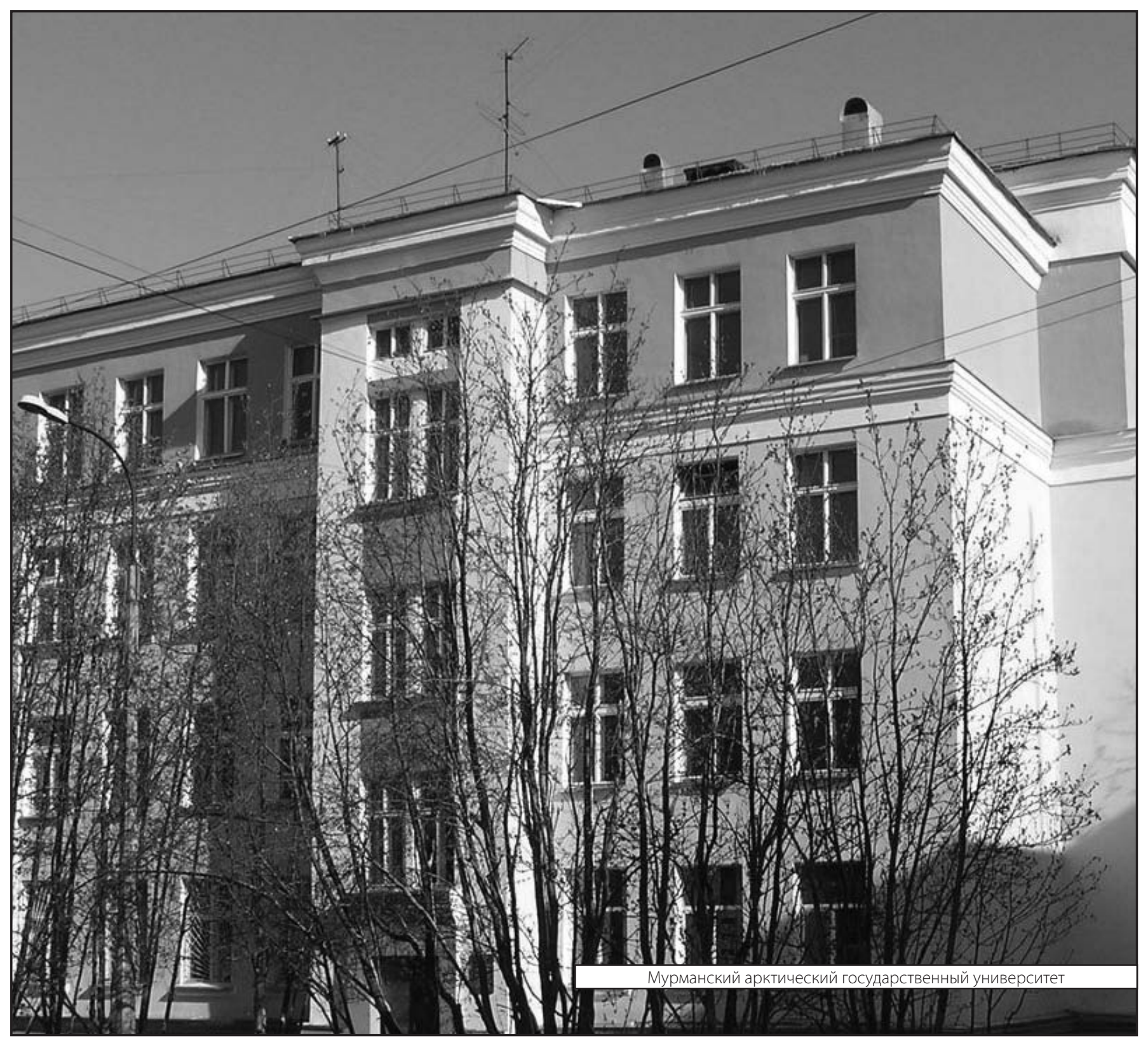

